Article

\title{
Can Bone Compaction Improve Primary Implant Stability? An In Vitro Comparative Study with Osseodensification Technique
}

\author{
Alessandro Antonelli ${ }^{1, *(D)}$, Francesco Bennardo ${ }^{1}(\mathbb{D})$, Ylenia Brancaccio ${ }^{1}$, Selene Barone ${ }^{1}(\mathbb{D}$,

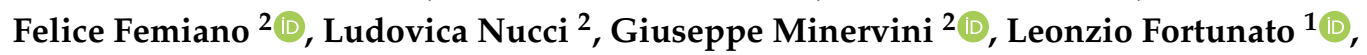 \\ Ferdinando Attanasio ${ }^{1}$ (D) and Amerigo Giudice ${ }^{1}$ (D) \\ 1 Department of Health Sciences, School of Dentistry, Magna Græcia University of Catanzaro, \\ 88100 Catanzaro, Italy; fbennardo92@gmail.com (F.B.); ybrancaccio@gmail.com (Y.B.); \\ barone.selene19@gmail.com (S.B.); leo@unicz.it (L.F.); ferdinando.attanasio@gmail.com (F.A.); \\ a.giudice@unicz.it (A.G.) \\ 2 Multidisciplinary Department of Medical-Surgical and Dental Specialties, University of Campania, \\ Luigi Vanvitelli, 80138 Naples, Italy; femiano@libero.it (F.F.); ludovica.nucci@unicampania.it (L.N.); \\ minervinigiuseppe@hotmail.it (G.M.) \\ * Correspondence: antonellicz@gmail.com; Tel.: +961-712-446
}

Received: 4 November 2020; Accepted: 29 November 2020; Published: 2 December 2020

\begin{abstract}
Background: This study aims to analyze bone compaction and osseodensification techniques and to investigate how cancellous bone compaction could influence primary implant stability (PS). Methods: Two different surgical protocols (bone compactors-BC; osseodensification drills-OD) were compared by placing 20 implants into 20 fresh pig ribs for each procedure. Peak insertion torque (PIT) and peak removal torque (PRT) were investigated using an MGT-12 digital torque gauge, and implant stability quotient (ISQ) was analyzed using an Osstell ${ }^{\circledR}$ Beacon device. Results: Analysis of our data (T-test $p<0.05$ ) evidenced no statistically significant difference between BC and OD in terms of PIT ( $p=0.33$ ) or ISQ $(p=0.97)$. The comparison of PRT values showed a statistically significant difference between $B C$ and OD protocols $(p=0.009)$. Conclusions: Cancellous bone compaction seems to improve PS, preserving a significant amount of bone and evenly spreading trabeculae on the entire implant site. While the PIT and ISQ values obtained are similar, the PRT values suggest different physical responses from the surrounding bone tissue. Nevertheless, a larger sample and further in vivo studies are necessary to validate the usefulness of $\mathrm{BC}$ protocol in several clinical settings.
\end{abstract}

Keywords: primary implant stability; osseodensification; bone compaction; resonance frequency analysis; insertion torque

\section{Introduction}

Dental implants are widely used nowadays for the rehabilitation of edentulous jaws [1]. One of the most important aims of implant rehabilitation is implant stability [1]. This can be obtained from the mechanical relationship between the fixture and the surrounding bone at implant placement (primary implant stability), or from the biological osseointegration process that occurs in the subsequent healing stages of the implant site (secondary implant stability) [1,2]. Primary implant stability (PS) is influenced by several variables, such as the implant shape, the surgical procedure used and the bone quantity and quality [3,4], whereas secondary stability is negatively conditioned by systemic factors such as age, smoking, autoimmune disease, metabolic disease, neoplasms and drug-related pathologies [5-7]. A good PS is required to enable an immediate-loading protocol and to achieve long-term stability [8]. Over the years, immediate loading of dental fixtures has been exploited due to the reduction in 
treatment time and trauma, and to considerations of aesthetics and the psychological wellness of the patient $[8,9]$.

Many authors have noted that PS is achieved when implant micro-motion has thresholds lower than 50 to $150 \mu \mathrm{m}$ before osseointegration occurs [10]. Usually PS is easily obtainable in jaw areas that have a greater amount of mineralized bone, such as the symphysis region. Over the years, many studies have shown that the highest implant failure rates were found in the posterior areas of the jaws and that surgery plays a main role in the rehabilitation of these zones [11,12]. The frequent lack of PS in these areas has led to the development of numerous surgical protocols that help to increase primary stability [13]. While the most common method for implant site preparation is bone drilling, this protocol increases PS only in soft bone due to under-preparation of the implant bed.

Over the years, researchers have analyzed the shape of the implant used in addition to the surgical technique. Several authors have focused on the advantage of using a specific implant design over others in the search for primary stability. In particular, it has been highlighted that the apical portion of an implant can play a fundamental role in the osseointegration process [14,15].

Several surgical techniques have been developed to increase the amount of bone surrounding the fixture. In particular, researchers have aimed to modify bone quality close to the implant threads. The osseodensification drill (OD) technique uses universal tapered drills (OD) that can operate in a clockwise or counterclockwise direction, cutting or expanding the trabecular bone. These drills used in a counterclockwise direction can produce an osseous densification all along the implant site, causing plastic bone compaction $[3,16]$. Recently, a manual osteotomy protocol was introduced by B\&B dental implant (San Benedetto, BO, Italy), which uses customized manual bone compactors (BC) to improve bone density. This surgical protocol involves the lateral spread of the bone walls of the implant site, taking advantage of bone elasticity to deform the trabeculae slowly [17]. To analyze PS, several parameters have been proposed in the literature; among these, peak insertion torque (PIT), peak removal torque (PRT) and implant stability quotient (ISQ) are the main methods to successfully investigate the implant stability [18]. The aim of the present study was to analyze any differences between the bone compaction and osseodensification techniques and to investigate how the bone compaction technique could influence primary implant stability (PS) in cancellous bone (type III and IV). The authors hypothesized no difference exists in PS values among the procedures.

\section{Materials and Methods}

The study was performed at the Dental Clinic of the Magna Graecia University of Catanzaro. Forty $\varnothing 4.0 \times 10 \mathrm{~mm}$-long tapered implants (3P, B\&B Dental, San Benedetto, BO, Italy) were placed in 20 fresh pig ribs (Figure 1).

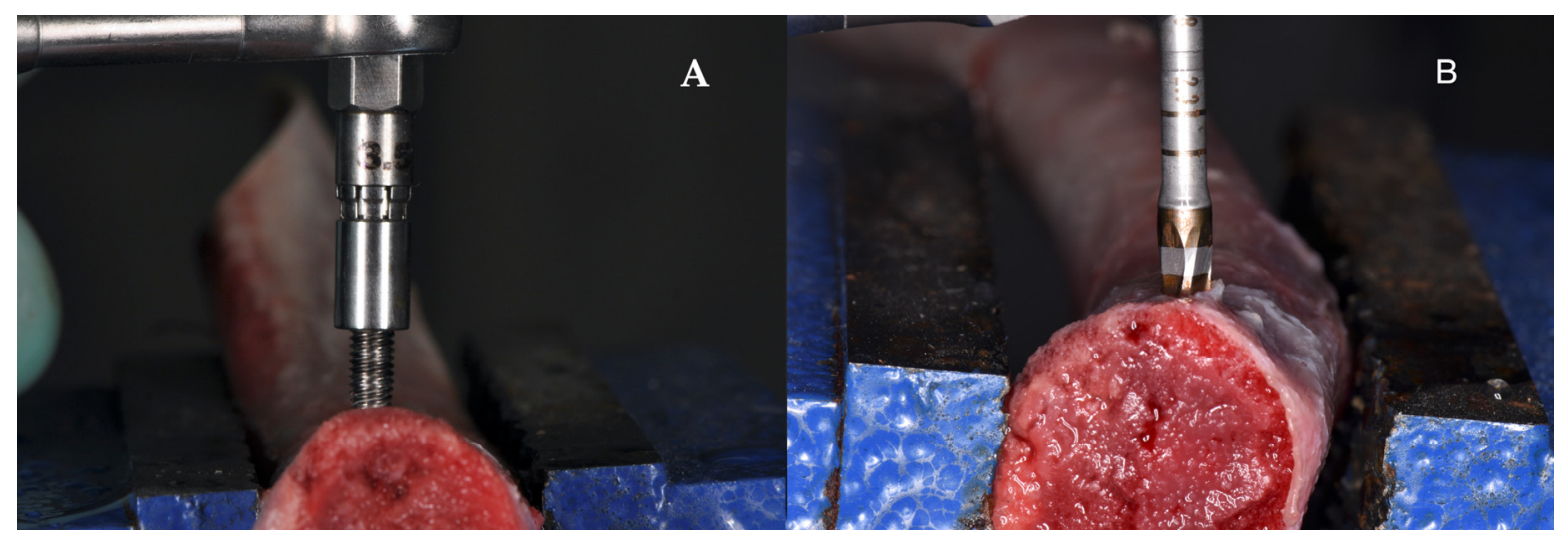

Figure 1. Surgical protocols performed in cancellous bone: Bone compaction implant site preparation (A); osseodensification implant site preparation (B). 


\subsection{Pre-Surgical Procedures}

The pig ribs were selected from a slaughterhouse, and the soft tissues were dissected exposing the bone. To investigate bone density, each rib was scanned with CBCT scan (Pax i-3d Green, Vatech, Yongin, Korea) using the Hounsfield measurement unit (HU), and 20 pig ribs were selected that matched the study inclusion criteria:

(1) $750<\mathrm{HU}$ bone density [19], to simulate type III and IV human bone (according to the Lekholm-Zarb classification) [20];

(2) bone height $\geq 12 \mathrm{~mm}$;

(3) bone thickness $\geq 6 \mathrm{~mm}$.

\subsection{Surgical Procedures}

The surgical protocol used to place each implant was randomly chosen using closed envelopes. Each pig rib received two dental implants, one placed via the bone compaction technique and one placed via the osseodensification technique. Pig ribs were fixed on a bench-vice, avoiding micro-movements during the surgical and recording procedures. Each surgical procedure was performed by the same expert surgeon.

The 3P tapered implant $\varnothing 4.0 \times 10 \mathrm{~mm}$-long (B\&B Dental, San Benedetto, BO, Italy) had a coronal diameter of $4.0 \mathrm{~mm}$ and an apical diameter of $3.2 \mathrm{~mm}$.

\subsubsection{Bone Compaction Implant Site Preparation}

Implant sites were prepared as suggested by the manufacturer using manual bone compactors with increasing diameter. The osteotomy started with the $1.7 \mathrm{~mm}$ diameter pilot drill. Subsequently, the implant beds were prepared with a manual rotational movement using tapered bone compactors (2.2 $\mathrm{mm} \varnothing-3.0 \mathrm{~mm} \varnothing-3.5 \mathrm{~mm} \varnothing$ and finished with the $4.0 \mathrm{~mm} \varnothing$ ). The major diameter of the last compactor was $3.7 \mathrm{~mm}$ and the minor diameter was $2.7 \mathrm{~mm}$.

\subsubsection{Osseodensification Implant Site Preparation}

Universal drills with a particular tapered design (Densah Bur, Versah LLC, Jackson, MI, USA) operating clockwise or counterclockwise were used for this protocol. Surgical procedures started using a pilot drill of $1.7 \mathrm{~mm}$ diameter, followed by a tapered universal drill with incremental diameters of $2.3 \mathrm{~mm}$ (ref. VT1828) and finished with $3.3 \mathrm{~mm}$ (ref. VT2838) with counterclockwise rotation, except for the pilot drill. The major diameter of the last drill was $3.8 \mathrm{~mm}$ and the minor diameter was $2.8 \mathrm{~mm}$.

\subsection{Primary Implant Stability Analysis}

Implants were manually inserted $1 \mathrm{~mm}$ under the level of cortical bone using the MGT-12 digital torque gauge device (Mark-10 Corp, New York, NY, USA). The increase in insertion force was $0.5 \mathrm{~mm} \mathrm{~min}^{-1}$, recording the peak insertion torque (PIT) in $\mathrm{Ncm}$. For each implant, ISQ was recorded by performing the resonance frequency analysis with the Osstell ${ }^{\circledR}$ Beacon device (W\&H, Göteborg, Sweden) and by screwing a customized SmartPeg. The resonance frequency was measured with a no-contact technique thanks to the magnetic waves produced by the Osstell ${ }^{\circledR}$ Beacon. Two measurements of ISQ (BL and MD) were performed for each fixture, directing the probe laterally in relation to the transducer. Operators repeated each measurement at least three times to validate the ISQ values, and the highest value was taken as reference for the statistical analysis. At the end of the measurements, each implant was unscrewed by the same MGT-12 digital torque device, and the peak removal torque (PRT) was recorded in $\mathrm{Ncm}$. All the procedures were performed by the same independent operator (Figure 2). 


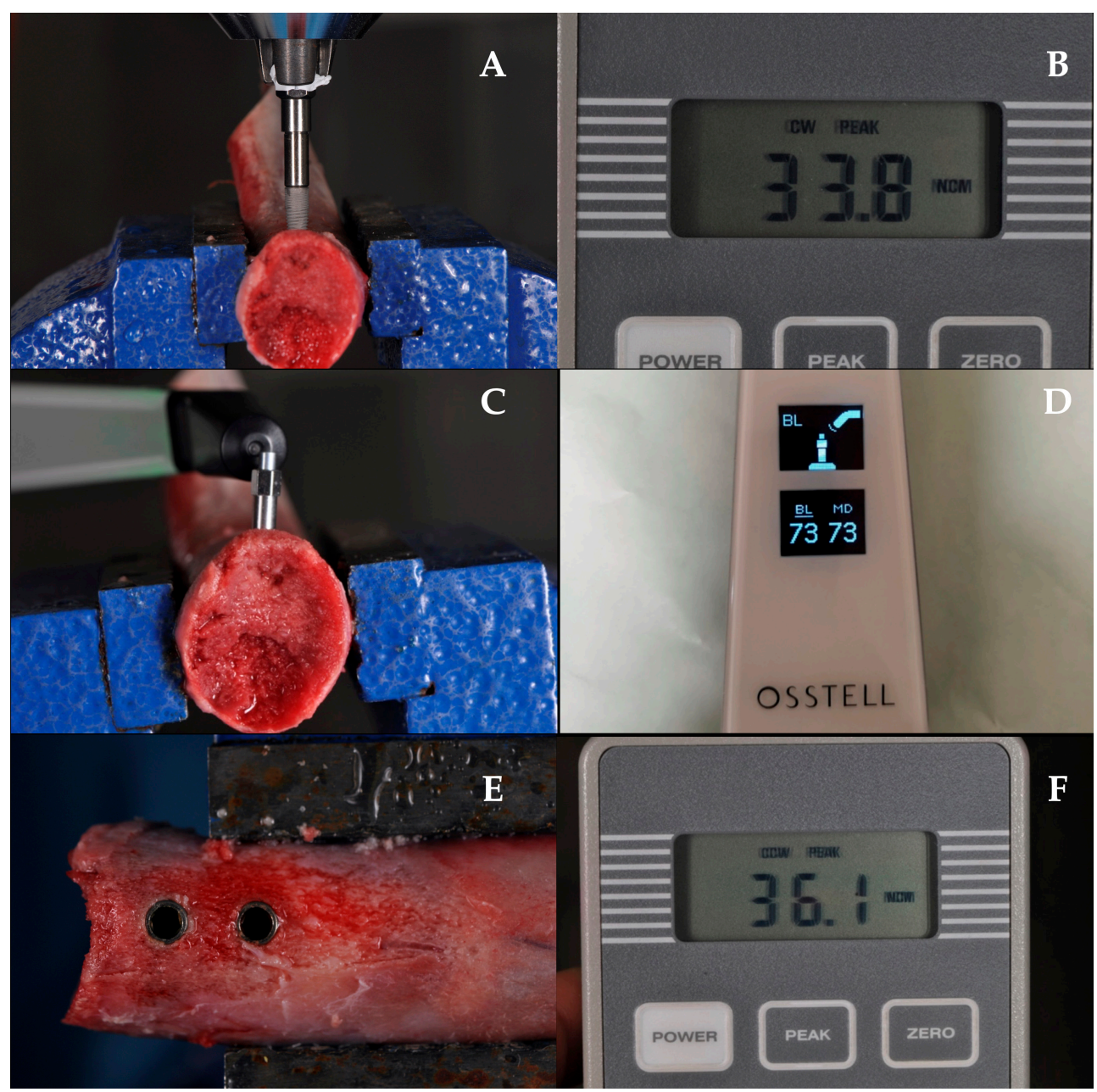

Figure 2. Primary implant stability analysis: Dental implant placement and recording of peak insertion torque (PIT) (A,B); measurement of implant stability quotient (ISQ) with a no-contact technique enabled by the magnetic waves produced by the Osstell ${ }^{\circledR}$ Beacon $(\mathbf{C}, \mathbf{D})$; fixtures placed and recording of peak removal torque (PRT) (E,F).

\subsection{Statistical Analysis}

The minimum sample size was computed with respect to T-test using the software $G^{*}$ Power (Heinrich-Heine-Universität, Düsseldorf), considering a difference between the two groups; $\mathrm{N}=40$ for sample; $n=20$ for each group; $|\mathrm{f}|>80 \% ; \alpha=0.05$ as the probability of type I error; $\beta=0.15$ as the probability of type II error.

To perform the statistical analysis we used the software SPSS Statistics (IBM Corp. Released 2017. IBM SPSS Statistics for Windows, Version 25.0. Armonk, NY: IBM Corp). Data were described as means and SD, and differences among groups were assessed by analysis of variance (T-test); statistically significant differences were considered when $p<0.05$.

\section{Results}

Forty implants were placed in 20 fresh pig ribs using two different osteotomy techniques: 20 implants were placed using the bone compactors protocol and 20 implants were placed according to the osseodensification drills procedure. Implants placed according to the bone compactors protocol showed a PIT mean of $41.55 \pm 9.12 \mathrm{Ncm}$, an ISQ mean of $75.5 \pm 3.89$ and a PRT mean of $45.37 \pm 7.8 \mathrm{Ncm}$. For implants placed using the osseodensification drills protocol, the PIT mean was $38.91 \pm 7.76 \mathrm{Ncm}$, the ISQ mean was $75.55 \pm 5.76$ and the PRT mean was $36.7 \pm 9.82 \mathrm{Ncm}$. T-test was performed to 
compare data among the two different groups. Statistically significant differences were observed only in removal torque parameter $(p=0.009)$. Data are showed in Table 1.

Table 1. Means and SD of PIT, ISQ and PRT for each group and results of T-test.

\begin{tabular}{cccc}
\hline $\begin{array}{c}\text { PIT } \\
\text { (Insertion Torque) } \mathbf{( N c m )}\end{array}$ & Sample Size & Mean & SD \\
\hline BC & 20 & 41.55 & 9.12 \\
OD & 20 & 38.91 & 7.76 \\
\hline$p$-value & 0.33 & & \\
\hline ISQ & Sample size & Mean & SD \\
\hline (Implant stability quotient) & 20 & 75.5 & 3.89 \\
\hline BC & 20 & 75.55 & 5.76 \\
OD & 0.97 & & \\
\hline$p$-value & Sample size & Mean & \\
\hline PRT & 20 & 45.37 & 7.8 \\
(Removal Torque) (Ncm) & 20 & 36.7 & 9.82 \\
\hline BC & $0.009 *$ & & \\
\hline OD & & & \\
\hline$p$-value & & & \\
\hline$p<0.05 *$ Statstcally & & \\
\hline
\end{tabular}

$p<0.05 ;{ }^{*}$ Statistically significant differences $p<0.05$.

Data distributions are summarized in the graphics (Figures 3-5).

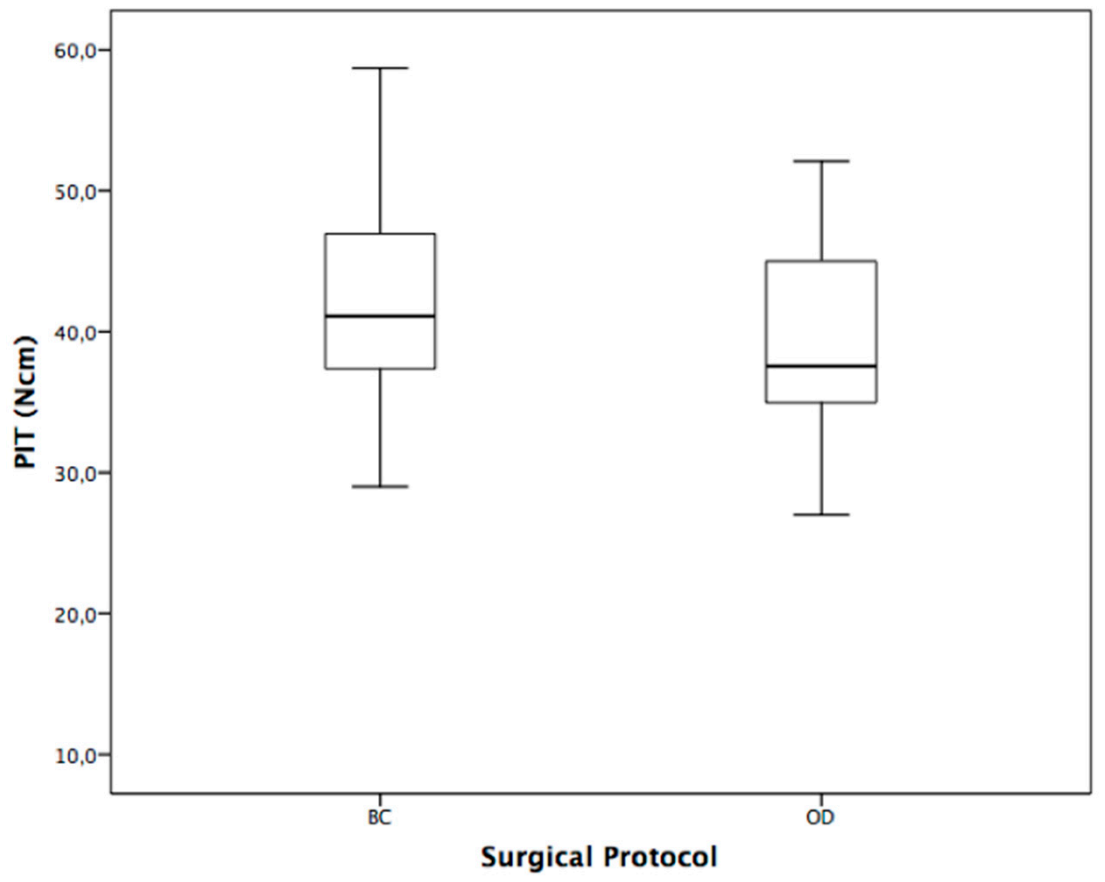

Figure 3. Box plot-insertion torque. 


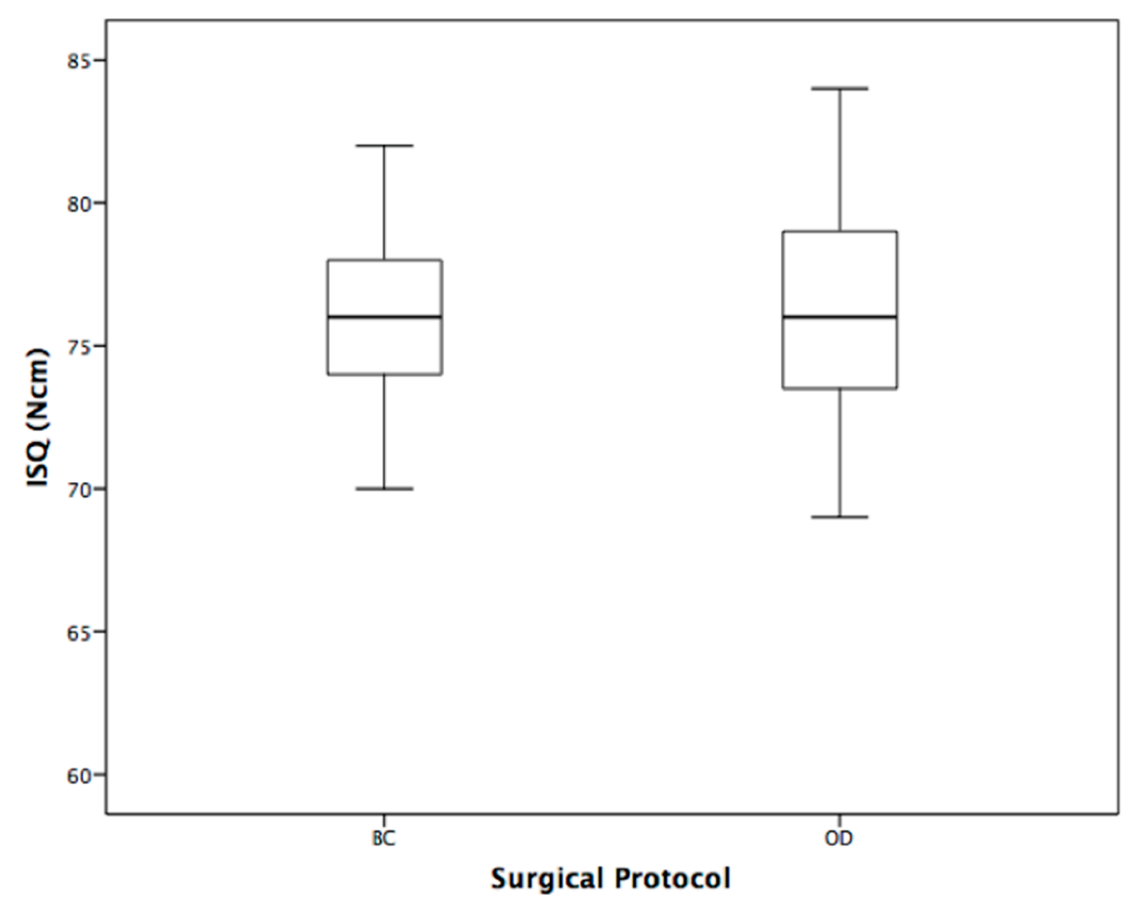

Figure 4. Box plot—implant stability quotient (ISQ).

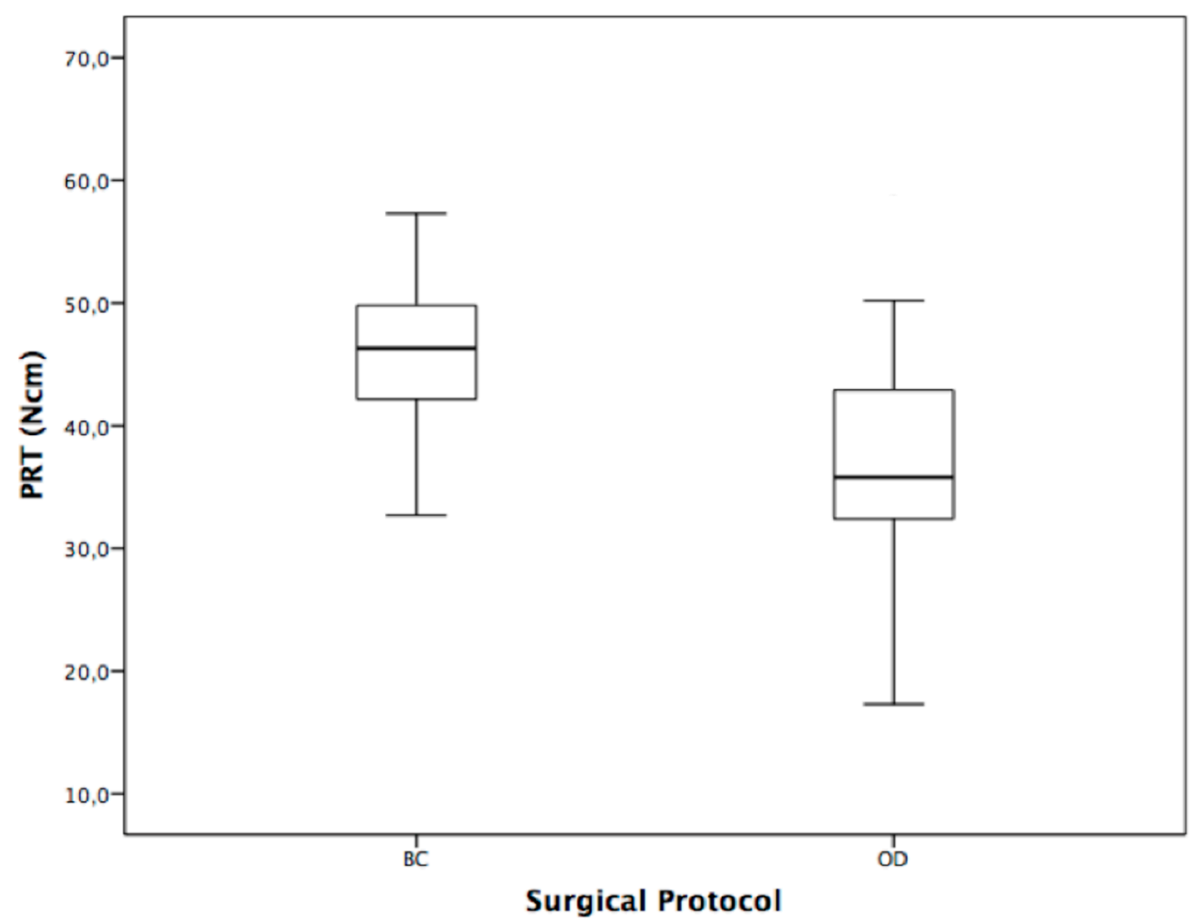

Figure 5. Box plot-removal torque.

\section{Discussion}

This study aimed to evaluate any advantages and differences between two surgical protocols in terms of PS enhancement in cancellous bone. Bone height and density are two of the main parameters considered for a predictable successful result in implantology. Several factors such as patient's age, osteometabolic disease and neoplasms can influence bone mineral density [21]. Ordinarily, the symphysis area is characterized by a greater amount of high-density bone, followed by 
the premaxilla, then the posterior areas of the lower and upper jaw [22]. A study by Holahanan et al. found significantly worse survival rates for implants placed in moderate/poor bone quality compared with those placed in good bone quality [23]. Furthermore, Vervaeke et al., in a retrospective cohort study analyzing predictors of implant failure, evidenced major peri-implant bone loss in the maxilla compared with the mandible [24]. Nevertheless, bone quality is not the only factor crucial to achieving success in the implant rehabilitation of edentulous jaws. In the last few decades, several types of implant design and surgical protocols have also been developed and tested to increase primary stability success rates $[25,26]$. In particular, several authors have noted how surgical procedures may influence primary implant stability in areas with the greatest amount of cancellous bone [3,17]. An improvement in PS values in soft bone can lead to greater predictability of the success of implant treatment.

While several studies have shown that under-preparation of the implant site gives excellent results in terms of PS [27], this procedure removes bone tissue without affecting the surrounding bone quality and may cause healing impairment [28,29]. The Summers' osteotomes technique was introduced for the crestal approach in maxillary sinus augmentation, causing a layer of compacted bone in the apical region [30]. This procedure, in particular, was widely used to allow implant placement in the case of reduced bone height in the posterior maxillary zones; however, this method does not produce any significant change in the surface of the implant site walls.

In our study, we considered two different surgical techniques, one using bone compactors and the other using osseodensification drills, to enhance PS values in poor bone quality. Primary stability was evaluated by insertion torque, resonance frequency analysis and removal torque, which today represent the gold standard indicators for implant stability [31].

While greater PIT mean value was recorded for the BC group, the minimal difference in terms of coronal diameter ( $3.7 \mathrm{~mm} \mathrm{BC}$ and $3.8 \mathrm{~mm} \mathrm{OD}$ ) and apical diameter $(2.7 \mathrm{~mm} \mathrm{BC}$ and $2.8 \mathrm{~mm} \mathrm{OD})$ did not indicate a significant difference in terms of PIT.

The implant stability quotient (ISQ) value is a parameter obtained during resonance frequency analysis (RFA). RFA was defined by Sennerby et al. as a bending test of the implant-bone complex wherein a transducer applies an extremely small bending force [30]. During this test, the fixture is subjected to lateral force that simulates the conditions of the clinical load, measuring implant displacement and the stiffness between the implant and the surrounding bone walls.

According to the literature, there is no clear correlation between PIT and ISQ. Furthermore, ISQ is not an effective one-time measurement parameter; however, it is designed to be a time-related parameter [31].

Our data analysis evidenced no significant differences in terms of ISQ between the two groups. High PIT and ISQ values represent the parameters of good primary implant stability, suggesting a strong stiffness at the implant-bone interface for both groups.

Clinical data and reviews have shown the effectiveness of the osseodensification procedure in improving primary and secondary stability in medullary bone [32,33]; as evidenced in several experimental in vivo and clinical studies, the osseodensification procedure has been proven to obtain the implant osseointegration from a biomechanical and histological point of view, using many implant microgeometry [34-36].

This concept, supported by histomorphometric and clinical analysis, showed how performing this surgical technique in soft bone can increase the primary implant stability values, promoting new bone formation around the fixture, providing greater stability [37-41].

Further clinical studies are required to analyze how implant stability varies during the healing period subsequent to the two surgical procedures.

While a limitation of this study is the absence of a quantitative analysis of bone density on micro-CT, the osteotomies $\mathrm{CT}$ images showed an increased bone density along the entire implant bed for both procedures (Figure 6). 

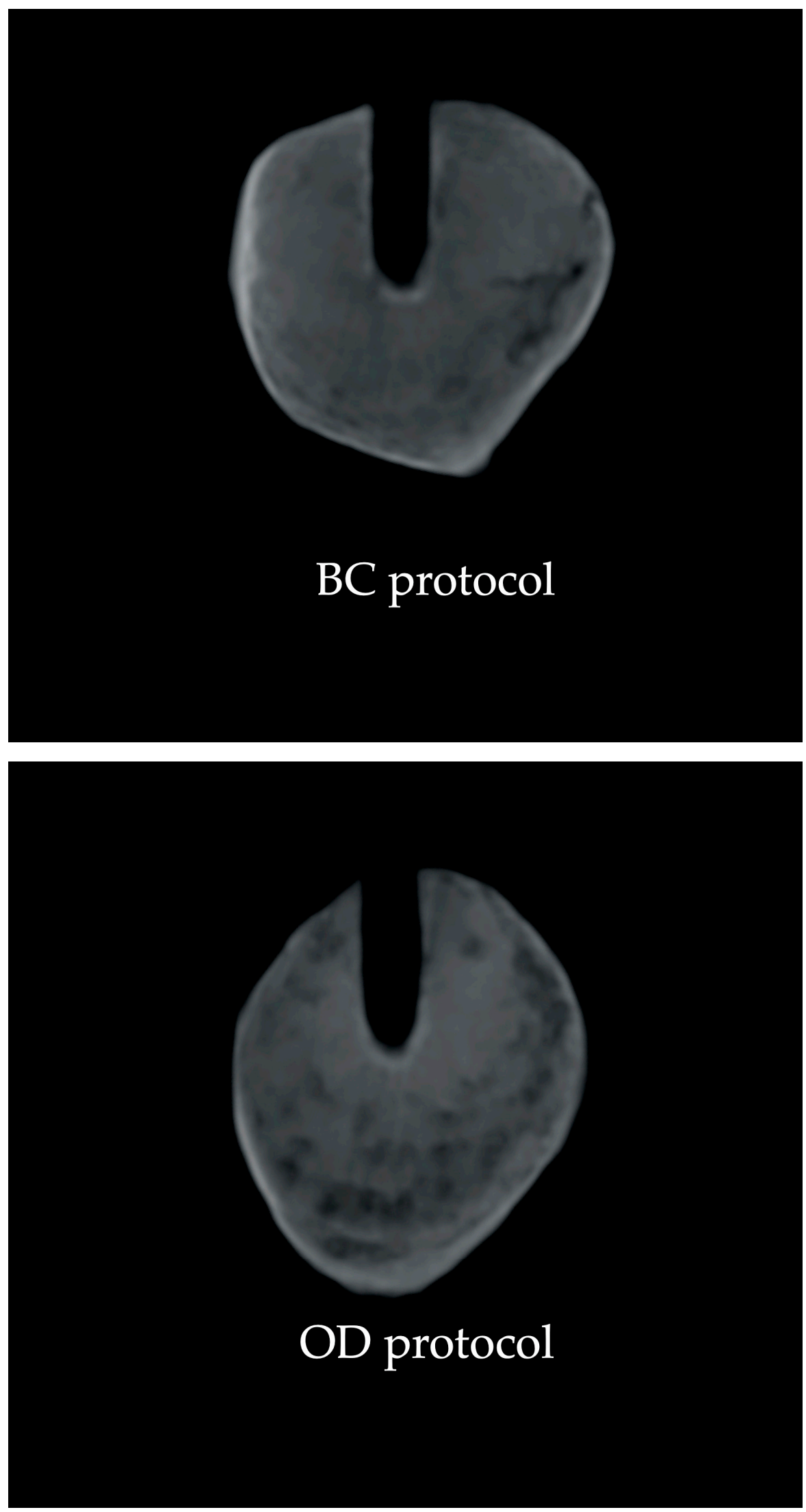

Figure 6. CBCT scans show a hyperdense border along the implant bone walls at the end of the osteotomies procedures: Bone compactors (BC); osseodensification drills (OD). 
As suggested by other authors, good compaction of bone trabeculae in bone marrow may justify high ISQ values, especially in the crestal region [31,42,43].

Removal torque does not provide data on implant stability directly, but rather represents a parameter indicating the relationship between bone and implant surface, especially for in vitro and ex vivo studies [44]. In fact, removal torque testing is not a well-documented clinical stability parameter in the literature.

In our study, both BC and OD protocols showed high PRT values. This report shows that surgical procedures involving bone changes allow a closer relationship between implant fixture and the surrounding bone, obtaining a better implant stability in the post-immediate implant placement [17]. This is a major requirement for protocols that involve immediate loading [45-47]. In particular, a statistically higher PRT value was found in the BC protocol compared with the value found in the OD technique. As stated by other authors, the use of Densah drills involves the plastic deformation of bone particles along the length of the osteotomy [3]; nevertheless, bone compaction performed by manual bone spreaders helps to create a similar effect of a gradual elastic deformation, preserving collagen integrity [3,17]. These concepts translate into better redistribution of the material with less compressive force than mechanical protocols.

Both BC and OD are bone preservation methods. They are vastly different to under-preparation standard drilling to create a misfit method. In our study, both groups of osteotomies were not undersized and were within 0.2 to $0.3 \mathrm{~mm}$ smaller than the implant major diameter.

As recently assessed in a preclinical study implant site, under-preparation with standard extraction drilling to create a misfit would lead to osteodestruction and the stress/strain linked to the severe downsized osteotomy could affect BIC and implant stability [29]. In fact, the micro-fractures performed in the peri-implant bone can cause a huge zone of dying osteocytes [48]. High interfacial pressures and mechanical under-preparation seem to produce a pro-resorptive environment as indicated by the lack of alkaline phosphatase activity and collagen I. Several authors assessed that the osseodensification technique produces bone chips usable as autografts during implant site preparation [49]. This phenomenon could play a main role in the implant site healing thanks to the osteogenesis and osteoconductive properties of the autologous bone chips.

The manual bone compaction procedure represents a less invasive method allowing maintenance of a greater amount of bone compared with standard drilling procedures, with a progressive compaction of the bone trabeculae carefully controlled by the clinician during the surgical phases [17].

The analysis of the values recorded in our study showed an excellent primary stability can be achieved performing both techniques. While the ISQ measurement did not reflect any significance value specially in any human clinical oral sites [50,51], the high values recorded suggest a condition favourable to the osseointegration phenomenon. Moreover, the PIT values represent a more predictive parameter for the evaluation of the relationship between the implant surface and the surrounding bone during the implant placement, especially in clinical situations [52]. Furthermore, insertion torque and ISQ are assessed as independent and incomparable methods of measuring PS [53]. Primary implant stability could be underestimated, mostly in the presence of medium or low values of PIT and ISQ, showing insufficiency in preventing errors when an immediate loading technique is performed [54].

This study was designed to analyze two surgical protocols and the primary stability values obtained in cancellous bone.

The pig ribs used in our study represent a suitable model according to the literature $[3,17,55]$. This model was used due to the homogeneous and simple geometry of the pig ribs, and the presence of a large amount of cancellous bone in the distal part.

One of the study limitations is the absence of temperature recording during the implant site osteotomies. In the literature, the influence of increasing temperature on implant stability and on osseointegration has been carefully analyzed [56-59]. Some authors have stated that drilling modalities can influence heat generation in low-density bone [60]. Other studies evaluated the drill materials and 
the impact on temperature changes, particularly in the apical portion of the implant bed [61]. However, we did not consider temperature alterations as a variable in this study.

Moreover, this research presents all the limitations of an in vitro study such as the absence of the implant osseointegration and the evaluation of the BIC (bone-implant contact) at the end of the healing process.

In vivo studies are necessary to evaluate how primary implant stability could be influenced by these surgical procedures in cancellous bone. Surgical parameters such as bleeding and overheating may also affect the healing response in vivo [57,62]. The use of an in vitro animal sample does not allow investigation of any intraoperative complications that could occur during surgical procedures with complex patients [63-65].

\section{Conclusions}

Despite the study limitations, our in vitro results demonstrate that both bone compaction and osseodensification technique positively affect the primary implant stability values in cancellous bone. Bone density and the relationship between bone walls and implant surface seem to be influenced by bone compaction along the entire implant bed, allowing for higher PIT, ISQ and PRT values. Moreover, the use of manual bone spreaders preserves a significant amount of bone, exploiting the elastic feature of the soft bone, positively improving the implant primary stability. Nevertheless, several in vivo studies are required to analyze any possible difference between the surgical techniques (BC and OD) performed in this study, in terms of histological healing and long- term clinical data with success rates.

Author Contributions: Conceptualization, A.A.; methodology, A.A. and F.A.; software, Y.B.; validation, F.B., S.B. and L.F.; formal analysis, Y.B and S.B.; investigation, G.M. and A.G.; resources, F.A.; data curation, Y.B.; writing-original draft preparation, A.A.; writing-review and editing, A.G.; visualization, F.F. and L.N.; supervision, F.A. and L.F.; project administration, A.A. and A.G. All authors have read and agreed to the published version of the manuscript.

Funding: This research received no external funding.

Acknowledgments: Thanks to the company B\&B Dental, San Benedetto, BO, Italy for providing free of charge the materials used in this study.

Conflicts of Interest: The authors declare no conflict of interest.

\section{Abbreviations}

$\begin{array}{ll}\text { OD } & \text { Osseodensification drills } \\ \text { BC } & \text { Bone compactors } \\ \text { PS } & \text { Primary implant stability } \\ \text { PIT } & \text { Peak insertion torque } \\ \text { RFA } & \text { Resonance frequency analysis } \\ \text { ISQ } & \text { Implant stability quotient } \\ \text { PRT } & \text { Peak removal torque }\end{array}$

\section{References}

1. Makary, C.; Menhall, A.; Zammarie, C.; Lombardi, T.; Lee, S.Y.; Stacchi, C.; Park, K.B. Primary Stability Optimization by Using Fixtures with Different Thread Depth According to Bone Density: A Clinical Prospective Study on Early Loaded Implants. Materials 2019, 12, 2398. [CrossRef]

2. Monje, A.; Ravidà, A.; Wang, H.L.; Helms, J.A.; Brunski, J.B. Relationship between Primary/Mechanical and Secondary/Biological Implant Stability. Int. J. Oral Maxillofac. Implant. 2019, 34, s7-s23. [CrossRef]

3. Huwais, S.; Meyer, E.G. A Novel Osseous Densification Approach in Implant Osteotomy Preparation to Increase Biomechanical Primary Stability, Bone Mineral Density, and Bone-to-Implant Contact. Int. J. Oral Maxillofac. Implant. 2017, 32, 27-36. [CrossRef]

4. Di Stefano, D.A.; Arosio, P.; Perrotti, V.; Iezzi, G.; Scarano, A.; Piattelli, A. Correlation between Implant Geometry, Bone Density, and the Insertion Torque/Depth Integral: A Study on Bovine Ribs. Dent. J. 2019, 7, 25. [CrossRef] 
5. Duttenhoefer, F.; Fuessinger, M.A.; Beckmann, Y.; Schmelzeisen, R.; Groetz, K.A.; Boeker, M. Dental implants in immunocompromised patients: A systematic review and meta-analysis. Int. J. Implant. Dent. 2019, 5, 43. [CrossRef]

6. Guazzo, R.; Sbricoli, L.; Ricci, S.; Bressan, E.; Piattelli, A.; Iaculli, F. Medication-Related Osteonecrosis of the Jaw and Dental Implants Failures: A Systematic Review. J. Oral Implantol. 2017, 43, 51-57. [CrossRef] [PubMed]

7. Giudice, A.; Barone, S.; Diodati, F.; Antonelli, A.; Nocini, R.; Cristofaro, M.G. Can Surgical Management Improve Resolution of Medication-Related Osteonecrosis of the Jaw at Early Stages? A Prospective Cohort Study. J. Oral Maxillofac. Surg. 2020, 78, 1986-1999. [CrossRef] [PubMed]

8. Simonpieri, A.; Gasparro, R.; Pantaleo, G.; Mignogna, J.; Riccitiello, F.; Sammartino, G. Four-year post-loading results of full-arch rehabilitation with immediate placement and immediate loading implants: A retrospective controlled study. Quintessence Int. 2017, 48, 315-324. [CrossRef] [PubMed]

9. Giudice, A.; Barone, S.; Muraca, D.; Averta, F.; Diodati, F.; Antonelli, A.; Fortunato, L. Can Teledentistry Improve the Monitoring of Patients during the Covid-19 Dissemination? A Descriptive Pilot Study. Int. J. Environ. Res. Public Health 2020, 17, 3399. [CrossRef]

10. Trisi, P.; Perfetti, G.; Baldoni, E.; Berardi, D.; Colagiovanni, M.; Scogna, G. Implant micromotion is related to peak insertion torque and bone density. Clin. Oral Implant. Res. 2009, 20, 467-471. [CrossRef] [PubMed]

11. Herrmann, I.; Lekholm, U.; Holm, S.; Kultje, C. Evaluation of patient and implant characteristics as potential prognostic factors for oral implant failures. Int. J. Oral Maxillofac. Implant. 2005, 20, 220-230.

12. Stacchi, C.; Spinato, S.; Lombardi, T.; Bernardello, F.; Bertoldi, C.; Zaffe, D.; Mevins, M. Minimally Invasive Management of Implant-Supported Rehabilitation in the Posterior Maxilla, Part, I.I. Surgical Techniques and Decision Tree. Int. J. Periodontics Restor. Dent. 2020, 40, e95-e102. [CrossRef] [PubMed]

13. Stacchi, C.; De Biasi, M.; Torelli, L.; Robiony, M.; Di Lenarda, R.; Angerame, D. Primary Stability of Short Implants Inserted Using Piezoelectric or Drilling Systems: An In Vitro Comparison. J. Oral Implantol. 2019, 45, 259-266. [CrossRef] [PubMed]

14. Gehrke, S.A.; Pérez-Albacete Martínez, C.; Piattelli, A.; Shibli, J.A.; Markovic, A.; Calvo Guirado, J.L. The influence of three different apical implant designs at stability and osseointegration process: Experimental study in rabbits. Clin. Oral Implant. Res. 2017, 28, 355-361. [CrossRef] [PubMed]

15. Scarano, A.; Assenza, B.; Inchingolo, F.; Mastrangelo, F.; Lorusso, F. New Implant Design with Midcrestal and Apical Wing Thread for Increased Implant Stability in Single Postextraction Maxillary Implant. Case Rep. Dent. 2019, 2019, 9529248. [CrossRef] [PubMed]

16. Fanali, S.; Tumedei, M.; Pignatelli, P.; Inchingolo, F.; Pennacchietti, P.; Pace, G.; Piattelli, A. Implant primary stability with an osteocondensation drilling protocol in different density polyurethane blocks. Comput. Methods Biomech. Biomed. Eng. 2020, 25, 1-7. [CrossRef]

17. Attanasio, F.; Antonelli, A.; Brancaccio, Y.; Averta, F.; Figliuzzi, M.M.; Fortunato, L.; Giudice, A. Primary Stability of Three Different Osteotomy Techniques in Medullary Bone: An in Vitro Study. Dent. J. 2020, 8, 21. [CrossRef]

18. Giudice, A.; Bennardo, F.; Antonelli, A.; Barone, S.; Wagner, F.; Fortunato, L.; Traxler, H. Influence of clinician's skill on primary implant stability with conventional and piezoelectric preparation techniques: An ex-vivo study. J. Biol. Regul. Homeost. Agents 2020, 34, 739-745. [CrossRef]

19. Michael, R.N.; Carole, G. Bone classification: An objective scale of bone density using the computerized tomography scan. Clin. Oral Implant. Res. 2001, 12, 79-84.

20. Lekholm, U. Patient Selection and Preparation. Tissue-Integrated Prostheses: Osseointegration in Clinical Dentistry; Quintessence Publishing: Chicago, IL, USA, 1985; pp. 199-209.

21. Merheb, J.; Temmerman, A.; Rasmusson, L.; Kübler, A.; Thor, A.; Quirynen, M. Influence of Skeletal and Local Bone Density on Dental Implant Stability in Patients with Osteoporosis. Clin. Implant. Dent. Relat. Res. 2016, 18, 253-260. [CrossRef]

22. Figliuzzi, M.M.; Giudice, A.; Pileggi, S.; Pacifico, D.; Marrelli, M.; Tatullo, M.; Fortunato, L. Implant-Prosthetic Rehabilitation in Bilateral Agenesis of Maxillary Lateral Incisors with a Mini Split Crest. Case Rep. Dent. 2016, 2016, 3591321. [CrossRef]

23. Holahan, C.M.; Wiens, J.L.; Weaver, A.; Assad, D.; Koka, S. Relationship between systemic bone mineral density and local bone quality as effectors of dental implant survival. Clin. Implant. Dent. Relat. Res. 2011, 13, 29-33. [CrossRef] 
24. Vervaeke, S.; Collaert, B.; Cosyn, J.; Deschepper, E.; De Bruyn, H. A multifactorial analysis to identify predictors of implant failure and peri-implant bone loss. Clin. Implant. Dent. Relat. Res. 2015, 17 (Suppl. 1), e298-e307. [CrossRef] [PubMed]

25. Baldi, D.; Lombardi, T.; Colombo, J.; Cervino, G.; Perinetti, G.; Di Lenarda, R.; Stacchi, C. Correlation between Insertion Torque and Implant Stability Quotient in Tapered Implants with Knife-Edge Thread Design. Biomed. Res. Int. 2018, 2018, 7201093. [CrossRef]

26. Stacchi, C.; Bassi, F.; Troiano, G.; Rapani, A.; Lombardi, T.; Jokstad, A.; Sennerby, L.; Schierano, G. Piezoelectric bone surgery for implant site preparation compared with conventional drilling techniques: A systematic review, meta-analysis and trial sequential analysis. Int. J. Oral Implantol. 2020, 13, 141-158.

27. Degidi, M.; Daprile, G.; Piattelli, A. Influence of underpreparation on primary stability of implants inserted in poor quality bone sites: An in vitro study. J. Oral Maxillofac. Surg. 2015, 73, 1084-1088. [CrossRef] [PubMed]

28. Trisi, P.; Berardini, M.; Falco, A.; Podaliri Vulpiani, M. New Osseodensification Implant Site Preparation Method to Increase Bone Density in Low-Density Bone: In Vivo Evaluation in Sheep. Implant. Dent. 2016, 25, 24-31. [CrossRef] [PubMed]

29. Coyac, B.R.; Leahy, B.; Salvi, G.; Hoffmann, W.; Brunski, J.B.; Helms, J.A. A preclinical model links osseo-densification due to misfit and osseo-destruction due to stress/strain. Clin. Oral Implant. Res. 2019, 30, 1238-1249. [CrossRef] [PubMed]

30. Slete, F.B.; Olin, P.; Prasad, H. Histomorphometric Comparison of 3 Osteotomy Techniques. Implant. Dent. 2018, 27, 424-428. [CrossRef]

31. Sennerby, L.; Meredith, N. Implant stability measurements using resonance frequency analysis: Biological and biomechanical aspects and clinical implications. Periodontology 2000 2008, 47, 51-66. [CrossRef]

32. Padhye, N.M.; Padhye, A.M.; Bhatavadekar, N.B. Osseodensification-A systematic review and qualitative analysis of published literature. J. Oral Biol. Craniofac. Res. 2020, 10, 375-380. [CrossRef] [PubMed]

33. Elsayyad, A.A.; Osman, R.B. Osseodensification in Implant Dentistry: A Critical Review of the Literature. Implant. Dent. 2019, 28, 306-312. [CrossRef] [PubMed]

34. Lahens, B.; Neiva, R.; Tovar, N.; Alifarag, A.M.; Jimbo, R.; Bonfante, E.A.; Bowers, M.M.; Cuppini, M.; Freitas, H.; Witek, L.; et al. Biomechanical and histologic basis of osseodensification drilling for endosteal implant placement in low density bone. An experimental study in sheep. J. Mech. Behav. Biomed. Mater. 2016, 63, 56-65. [CrossRef] [PubMed]

35. Alifarag, A.M.; Lopez, C.D.; Neiva, R.F.; Tovar, N.; Witek, L.; Coelho, P.G. Atemporal osseointegration: Early biomechanical stability through osseodensification. J. Orthop Res. 2018, 36, 2516-2523. [CrossRef] [PubMed]

36. Koutouzis, T.; Huwais, S.; Hasan, F.; Trahan, W.; Waldrop, T.; Neiva, R. Alveolar Ridge Expansion by Osseodensification-Mediated Plastic Deformation and Compaction Autografting: A Multicenter Retrospective Study. Implant. Dent. 2019, 28, 349-355. [CrossRef] [PubMed]

37. Lopez, C.D.; Alifarag, A.M.; Torroni, A.; Tovar, N.; Diaz-Siso, J.R.; Witek, L.; Rodriguez, E.D.; Coelho, P.G. Osseodensification for enhancement of spinal surgical hardware fixation. J. Mech. Behav. Biomed. Mater. 2017, 69, 275-281. [CrossRef]

38. Huwais, S.; Mazor, Z.; Ioannou, A.L.; Gluckman, H.; Neiva, R. A Multicenter Retrospective Clinical Study with Up-to-5-Year Follow-up Utilizing a Method that Enhances Bone Density and Allows for Transcrestal Sinus Augmentation Through Compaction Grafting. Int. J. Oral Maxillofac. Implant. 2018, 33, 1305-1311. [CrossRef]

39. Tanello, B.; Huwais, S.; Tawil, I.; Rosen, P.; Neiva, R. Osseodensification protocols for enhancement of primary and secondary implant stability-A retrospective 5-year follow-up multi-center study. Clin. Oral Implant. Res. 2019, 30, 414. [CrossRef]

40. Gaspar, J.; Esteves, T.; Gaspar, R.; Rua, J.; João Mendes, J. Osseodensification for implant site preparation in the maxilla-a prospective study of 97 implants. Clin. Oral Implant. Res. 2018, 29, 163. [CrossRef]

41. Kumar, B.; Narayan, V. Minimally invasive crestal approach sinus floor elevation using Densah burs, and hydraulic lift utilizing putty graft in cartridge delivery. Clin. Oral Implant. Res. 2017, 28 (Suppl. 14), 203.

42. Vercellotti, T.; Troiano, G.; Oreglia, F.; Lombardi, T.; Gregorig, G.; Morella, E.; Rapani, A.; Stacchi, C. Wedge-Shaped Implants for Minimally Invasive Treatment of Narrow Ridges: A Multicenter Prospective Cohort Study. J. Clin. Med. 2020, 9, 3301. [CrossRef] [PubMed] 
43. Meredith, N.; Book, K.; Friberg, B.; Jemt, T.; Sennerby, L. Resonance frequency measurements of implant stability in vivo. A cross-sectional and longitudinal study of resonance frequency measurements on implants in the edentulous and partially dentate maxilla. Clin. Oral Implant. Res. 1997, 8, 226-233. [CrossRef]

44. Anitua, E.; Murias-Freijo, A.; Alkhraisat, M.H. Conservative Implant Removal for the Analysis of the Cause, Removal Torque, and Surface Treatment of Failed Nonmobile Dental Implants. J. Oral Implant. 2016, 42, 69-77. [CrossRef]

45. Stacchi, C.; Lombardi, T.; Baldi, D.; Bugea, C.; Rapani, A.; Perinetti, G.; Itri, A.; Carpita, D.; Audenino, G.; Bianco, G.; et al. Immediate Loading of Implant-Supported Single Crowns after Conventional and Ultrasonic Implant Site Preparation: A Multicenter Randomized Controlled Clinical Trial. Biomed. Res. Int. 2018, 2018, 6817154. [CrossRef] [PubMed]

46. Cozzani, M.; Nucci, L.; Lupini, D.; Dolatshahizand, H.; Fazeli, D.; Barzkar, E.; Naeini, E.; Jamilian, A. The ideal insertion angle after immediate loading in Jeil, Storm, and Thunder miniscrews: A 3D-FEM study. Int. Orthod. 2020, 18, 503-508. [CrossRef]

47. Minervini, G.; Romano, A.; Petruzzi, M.; Maio, C.; Serpico, R.; Lucchese, A.; Candotto, V.; Di Stasio, D. Telescopic overdenture on natural teeth: Prosthetic rehabilitation on (OFD) syndromic patient and a review on available literature. J. Biol. Regul. Homeost. Agents 2018, 32 (Suppl. 1), 131-134.

48. Ikar, M.; Grobecker-Karl, T.; Karl, M.; Steiner, C. Mechanical stress during implant surgery and its effects on marginal bone: A literature review. Quintessence Int. 2020, 51, 142-150. [CrossRef] [PubMed]

49. Witek, L.; Alifarag, A.M.; Tovar, N.; Lopez, C.D.; Gil, L.F.; Gorbonosov, M.; Hannan, K.; Neiva, R.; Coelho, P.G. Osteogenic parameters surrounding trabecular tantalum metal implants in osteotomies prepared via osseodensification drilling. Med. Oral Patol. Oral Cir. Bucal 2019, 24, e764-e769. [CrossRef]

50. González-García, R.; Monje, F.; Moreno-García, C. Predictability of the resonance frequency analysis in the survival of dental implants placed in the anterior non-atrophied edentulous mandible. Med. Oral Patol. Oral Cir. Bucal 2011, 16, e664-e669. [CrossRef] [PubMed]

51. Bischof, M.; Nedir, R.; Szmukler-Moncler, S.; Bernard, J.P.; Samson, J. Implant stability measurement of delayed and immediately loaded implants during healing. Clin. Oral Implants Res. 2004, 15, 529-539. [CrossRef]

52. Greenstein, G.; Cavallaro, J. Implant Insertion Torque: Its Role in Achieving Primary Stability of Restorable Dental Implants. Compend. Contin. Educ. Dent. 2017, 38, 88-95. [PubMed]

53. Lages, F.S.; Douglas-de Oliveira, D.W.; Costa, F.O. Relationship between implant stability measurements obtained by insertion torque and resonance frequency analysis: A systematic review. Clin. Implant. Dent. Relat. Res. 2018, 20, 26-33. [CrossRef]

54. Degidi, M.; Daprile, G.; Piattelli, A. Determination of primary stability: A comparison of the surgeon's perception and objective measurements. Int. J. Oral Maxillofac. Implants 2010, 25, 558-561. [PubMed]

55. Yao, C.J.; Ma, L.; Mattheos, N. Can resonance frequency analysis detect narrow marginal bone defects around dental implants? An ex vivo animal pilot study. Aust. Dent. J. 2017, 62, 433-439. [CrossRef]

56. Di Fiore, A.; Sivolella, S.; Stocco, E.; Favero, V.; Stellini, E. Experimental Analysis of Temperature Differences during Implant Site Preparation: Continuous Drilling Technique Versus Intermittent Drilling Technique. J. Oral Implantol. 2018, 44, 46-50. [CrossRef] [PubMed]

57. Fugito Junior, K.; Cortes, A.R.; de Carvalho Destro, R.; Yoshimoto, M. Comparative Study on the Cutting Effectiveness and Heat Generation of Rotary Instruments Versus Piezoelectric Surgery Tips Using Scanning Electron Microscopy and Thermal Analysis. Int. J. Oral Maxillofac. Implant. 2018, 33, 345-350. [CrossRef]

58. Marenzi, G.; Sammartino, J.C.; Scherillo, F.; Rengo, C.; Rosa, A.D.; Graziano, V.; Spagnuolo, G. Comparative Analysis of the Chemical Composition and Microstructure Conformation Between Different Dental Implant Bone Drills. Materials 2019, 12, 1866. [CrossRef]

59. Marenzi, G.; Sammartino, J.C.; Quaremba, G.; Graziano, V.; Hassanin, A.E.; Qorri, M.E.; Sammartino, G.; Iorio-Siciliano, V. Clinical Influence of Micromorphological Structure of Dental Implant Bone Drills. Biomed. Res. Int. 2018, 2018, 8143962. [CrossRef] [PubMed]

60. Möhlhenrich, S.C.; Abouridouane, M.; Heussen, N.; Hölzle, F.; Klocke, F.; Modabber, A. Thermal evaluation by infrared measurement of implant site preparation between single and gradual drilling in artificial bone blocks of different densities. Int. J. Oral Maxillofac. Surg. 2016, 45, 1478-1484. [CrossRef] 
61. Scarano, A.; Lorusso, F.; Noumbissi, S. Infrared Thermographic Evaluation of Temperature Modifications Induced during Implant Site Preparation with Steel vs. Zirconia Implant Drill. J. Clin. Med. 2020, 9, 148. [CrossRef]

62. Vercellotti, T.; Stacchi, C.; Russo, C.; Rebaudi, A.; Vincenzi, G.; Pratella, U.; Baldi, D.; Mozzati, M.; Monagheddu, C.; Sentineri, R.; et al. Ultrasonic implant site preparation using piezosurgery: A multicenter case series study analyzing 3579 implants with a 1- to 3-year follow-up. Int. J. Periodontics Restor. Dent. 2014, 34, 11-18. [CrossRef]

63. Lamas Pelayo, J.; Peñarrocha Diago, M.; Martí Bowen, E.; Peñarrocha Diago, M. Intraoperative complications during oral implantology. Med. Oral Patol. Oral Cir. Bucal. 2008, 13, E239-E243. [PubMed]

64. Brancaccio, Y.; Antonelli, A.; Barone, S.; Bennardo, F.; Fortunato, L.; Giudice, A. Evaluation of local hemostatic efficacy after dental extractions in patients taking antiplatelet drugs: A randomized clinical trial. Clin. Oral Investig. 2021, 25, 1159-1167. [CrossRef] [PubMed]

65. Monje, A.; Catena, A.; Borgnakke, W.S. Association between diabetes mellitus/hyperglycaemia and peri-implant diseases: Systematic review and meta-analysis. J. Clin. Periodontol. 2017, 44, 636-648. [CrossRef] [PubMed]

Publisher's Note: MDPI stays neutral with regard to jurisdictional claims in published maps and institutional affiliations.

(C) 2020 by the authors. Licensee MDPI, Basel, Switzerland. This article is an open access article distributed under the terms and conditions of the Creative Commons Attribution (CC BY) license (http://creativecommons.org/licenses/by/4.0/). 